\title{
ecosystem sources
}

3

Authors: Judith A. Rosentreter ${ }^{1,2 *}$, Alberto V. Borges ${ }^{3}$, Bridget R. Deemer ${ }^{4}$, Meredith A. Holgerson ${ }^{5,6}$, Shaoda Liu $^{2,7}$, Chunlin Song ${ }^{8,9}$, John Melack ${ }^{10}$, Peter A. Raymond ${ }^{2}$, Carlos M. Duarte $^{11}$, George H. Allen ${ }^{12}$, David Olefeldt ${ }^{13}$, Benjamin Poulter ${ }^{14}$, Tom I. Battin ${ }^{15}$, Bradley D. Eyre $^{1}$

*correspondence: judith.rosentreter@yale.edu

\section{Author Affiliations:}

${ }^{1}$ Centre for Coastal Biogeochemistry, School of Environment, Science and Engineering, Southern Cross University, Lismore, NSW, 2480, Australia

${ }^{2}$ Yale School of Forestry and Environmental Studies, 195 Prospect Street, New Haven, CT, USA

${ }^{3}$ University of Liège, Chemical Oceanography Unit, Liège, Belgium

${ }^{4}$ U.S. Geological Survey, Southwest Biological Science Center, Flagstaff, AZ, USA

${ }^{5}$ Departments of Biology and Environmental Studies, St. Olaf College, Northfield, Minnesota, USA

${ }^{6}$ Department of Ecology and Evolutionary Biology, Cornell University, Ithaca, NY, USA

${ }^{7}$ School of Environment, Beijing Normal University, No. 19 Xinjiekouwai Street, Haidian, Beijing, China

${ }^{8}$ Institute of Mountain Hazards and Environment, Chinese Academy of Sciences, Chengdu, Sichuan, China

${ }^{9}$ State Key Laboratory of Hydraulics and Mountain River Engineering, College of Water Resource and Hydropower, Sichuan University, Chengdu, Sichuan, China

${ }^{10}$ Bren School of Environmental Science and Management, University of California, Santa Barbara, California, 93106, USA

${ }^{11}$ King Abdullah University of Science and Technology (KAUST), Red Sea Research Center (RSRC) and Computational Bioscience Research Center (CBRC), Thuwal, 23955-6900, Saudi Arabia

${ }^{12}$ Department of Geography, Texas A\&M University, College Station, TX, USA

${ }^{13}$ Department of Renewable Resources, University of Alberta, Edmonton, Canada

${ }^{14}$ NASA Goddard Space Flight Center, Biospheric Sciences Lab., Greenbelt, MD 20816

${ }^{15}$ École Polytechnique Fédérale de Lausanne, 1015 Lausanne, Switzerland 
First paragraph:

Atmospheric methane is a potent greenhouse gas that plays a major role in controlling the Earth's climate. The causes of the renewed increase of methane concentration since 2007 are uncertain given the multiple sources and complex biogeochemistry. Here, we present a meta-data analysis of methane fluxes from all major natural, impacted and human-made aquatic ecosystems. Our revised bottom-up global aquatic methane emissions combine diffusive, ebullitive and plant-mediated and/or fluxes from several sediment-water-air interfaces. We emphasize the high variability of methane fluxes within and between aquatic ecosystems and a positively skewed distribution of empirical data, making global estimates sensitive to statistical assumptions and sampling design. We find aquatic ecosystems contribute (median) $41 \%$ or (mean) $53 \%$ of total global methane emissions from anthropogenic and natural sources. We show that methane emissions increase from natural to impacted aquatic ecosystems, and from coastal to freshwater ecosystems. We argue that aquatic emissions will likely increase due to urbanization, eutrophication and positive climate-feedbacks, and suggest changes in land-use management as potential mitigation strategies to reduce aquatic methane emissions.

\section{Main text:}

Methane $\left(\mathrm{CH}_{4}\right)$ is the second most important greenhouse gas after carbon dioxide $\left(\mathrm{CO}_{2}\right)$, accounting for 16 to $25 \%$ of atmospheric warming to date ${ }^{1,2}$. Atmospheric methane nearly tripled since pre-industrial times with a steady rise between 1984 and $2000\left(8.4 \pm 0.6 \mathrm{ppb} \mathrm{yr}^{-1}\right)^{3}$, little or

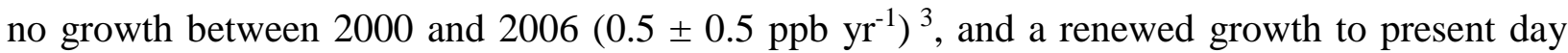

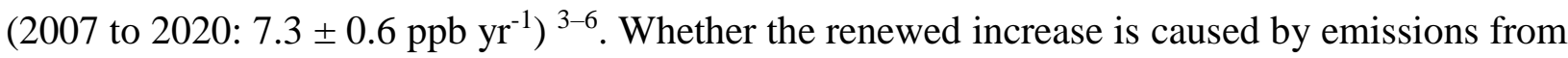
anthropogenic or natural sources, or by a decline in the oxidative capacity of the atmosphere, or a combination of all three factors remains unresolved ${ }^{7-9}$. Depending on the approach used, total 
methane emissions from natural and anthropogenic sources range between $538-884 \mathrm{Tg} \mathrm{CH}_{4} \mathrm{yr}^{-1}$ 10,11. However, top-down versus bottom-up estimates of methane sources and sinks do not match, underscoring the incomplete knowledge of global methane dynamics ${ }^{10,11}$.

Reducing the uncertainty in methane emission intensities and partitioning emissions to anthropogenic and natural sources is challenging. At the global scale, bottom-up methane emissions from aquatic ecosystems are not well-constrained due to reasons that include the lack of observations, uncertainties associated with surface areas, and the risk of 'double counting' of ecosystem types. In particular, methane emission from small lakes, reservoirs, aquaculture ponds, and coastal wetlands were insufficiently assessed in the IPCC $5^{\text {th }}$ Assessment report ${ }^{1}$ and in the most recent global methane budget ${ }^{11}$. Finally, anthropogenic disturbances such as dam construction ${ }^{12}$, eutrophication ${ }^{13}$, and wetland modification ${ }^{14}$, along with climate-feedbacks such as microbial responses to warming ${ }^{15}$ and changes in hydrology ${ }^{16,17}$, all lead to an alteration of methane fluxes that are currently difficult to account for at the global scale. A better understanding of the aquatic contribution to global methane emissions is therefore critical to a more robust understanding of atmospheric methane dynamics.

\section{Global aquatic methane emissions}

Here we present a meta-data analysis of aquatic methane flux measurements based on inventory, remote sensing and modeling efforts to revise bottom-up estimates of areal methane fluxes (mg CH $\mathrm{m}_{4}^{-2} \mathrm{~d}^{-1}$ ) (Supplementary Table 1) and global methane emissions ( $\mathrm{Tg} \mathrm{CH}_{4} \mathrm{yr}^{-1}$ ) (Table 1) from rivers and streams, lakes and ponds, reservoirs, estuaries, mangroves, saltmarshes, seagrasses, tidal flats, aquaculture ponds, continental shelves, along with recently published estimates of global methane emissions from freshwater wetlands ${ }^{11}$, rice paddies ${ }^{11}$, continental slope and open ocean ${ }^{18}$. Our global synthesis reveals median (Q1-Q3) methane emissions from aquatic ecosystems of 269 (202-424) $\mathrm{Tg} \mathrm{CH}_{4} \mathrm{yr}^{-1}$ or mean (lower-upper C.I.95\%) emissions of 
431 (343-519) $\mathrm{Tg} \mathrm{CH}_{4} \mathrm{yr}^{-1}$. Our bottom-up estimates show a larger range with a lower (median) or higher (mean) central tendency than the most recent bottom-up estimate for aquatic ecosystems and wetlands ${ }^{11}$ (Table 2). The interquartile range (IQR) (222 $\mathrm{Tg} \mathrm{CH}_{4} \mathrm{yr}^{-1}$ ) of our global aquatic emissions is larger than the confidence interval $\left(176 \mathrm{Tg} \mathrm{CH}_{4} \mathrm{yr}^{-1}\right)$, which suggests that methane flux variability is larger than uncertainty. The high variability in data sources is linked to the complexity of how methane is produced, transported, and consumed before reaching the atmosphere, with different transport pathways (i.e., diffusion, ebullition, plant-mediated), physical interfaces (water-atmosphere, sediment-atmosphere), ecosystem conditions (impacted versus natural), and temporal (diel/tidal, seasonal, inter-annual) and spatial scales involved. We find that the statistical distributions of our data sets are ecosystem-specific, and that all aquatic ecosystems have positively skewed distributions (Fig. 1), which greatly affects the results for global upscaling (Fig. 2). If the observational data represent the actual flux distribution, then mean values would be the appropriate measure to scale global emissions. However, our assessment cannot rule out substantial bias in the available flux estimates resulting from limited temporal and spatial coverage and non-random selection of study sites. Under such circumstances, median values provide a more conservative estimate for upscaling.

Methane emissions (Q1-Q3) from freshwater wetlands (138-165 $\mathrm{Tg} \mathrm{CH}_{4} \mathrm{yr}^{-1}$ ) and lakes (23-142 $\left.\mathrm{Tg} \mathrm{CH}_{4} \mathrm{yr}^{-1}\right)$ are the largest aquatic sources, followed by rice cultivation (25-32 $\mathrm{Tg} \mathrm{CH}$ $\left.\mathrm{yr}^{-1}\right)$, coastal ocean $\left(5-28 \mathrm{Tg} \mathrm{CH}_{4} \mathrm{yr}^{-1},<200 \mathrm{~m}\right)$, reservoir $\left(9-28 \mathrm{Tg} \mathrm{CH}_{4} \mathrm{yr}^{-1}\right)$, and river and stream emissions (2-21 $\mathrm{Tg} \mathrm{CH}_{4} \mathrm{yr}^{-1}$ ). While uncertainties for bottom-up (and top-down) global estimates are still high, natural, impacted and human-made aquatic ecosystems including wetlands could be equally important to, or greater than direct anthropogenic emissions ${ }^{11,19}$. Depending on the approach used (median or mean), we find that 41 or $53 \%$ of the global methane emissions can be attributed to aquatic ecosystems, whereas non-aquatic systems contribute the remainder, for example 8 or $6 \%$ to other land sources such as onshore geological, wild animals and termites ${ }^{11}$, 
121 and 51 or $41 \%$ to direct anthropogenic activities such as enteric fermentation and manure, landfill and waste, coal mining, gas and oil industry, transport, and biomass and biofuel burning ${ }^{11}$ (Table 2).

Our revised global estimates of aquatic ecosystem emissions are mostly higher than previous estimates (Supplementary Table 2). However, the comparison to previous studies is challenging due to the difference in upscaling methods, dissimilar statistical treatment, and uncertainties in surface areas. In brief, our combined lakes, ponds and reservoir emissions are higher than the first mean global estimate for these ecosystems ${ }^{20}$, similar to recent estimates based on chlorophyll $a$ scaling ${ }^{21}$, and lower than recent upscaling from mean values ${ }^{21}$ (Supplementary

130 Table 2). The relatively lower emissions we present here are largely the result of an 'ice' correction 131 term, which had not previously been implemented in the computation of global lake and reservoir emissions (Supplementary Table 2). Thus, while our mean annual emissions for lakes, ponds and reservoirs are not higher than recent estimates, mean areal methane fluxes are higher than those recently reported (132 $\left.\mathrm{mg} \mathrm{CH}_{4} \mathrm{~m}^{-2} \mathrm{~d}^{-1}\right)^{27}$ (Supplementary Table 2). These higher areal fluxes likely result from our inclusion of recent studies that add smaller waterbodies and whose methods capture

136 ebullitive ${ }^{22}$. The result is a database containing disproportionately more studies from research published since 2015 (205 of 313 lakes or reservoirs; 65\%). We find that the smallest lakes are responsible for the largest emission with $\sim 37 \%$ of total lake emission coming from lakes $<0.001$ $\mathrm{km}^{2}$ regardless of mean or median (Table 1).

Our ice-corrected river and stream emissions are significantly higher than the first reported 141 global mean ${ }^{1}$, which used a low surface area, only 21 sites for upscaling, and no data from the tropics. A more recent review ${ }^{23}$, using an updated surface area ${ }^{24}$ and 385 sites, reported an average

143 diffusive flux that is higher than our global estimate (Supplementary Table 2). Here we increase 144 the number of sites and include ebullitive fluxes to report fluxes from 5 latitudinal bands. 145 Approximately $30 \%$ of ice corrected fluxes are from the equatorial latitudes due to the large ice- 
146 free surface area of streams and rivers (Supplementary Table 3). However, the data density of total 147 and ebullitive fluxes are low, particularly for mid to high latitudes.

148 Our coastal ocean emission estimate is higher than previous mean estimates ${ }^{11,18,25}$, which 149 did not include some of the coastal habitats. The large range and uncertainty of coastal methane 150 fluxes that we find in this study are associated with the paucity of data, but also with the high spatial and temporal variability of fluxes in coastal ecosystems driven by e.g. tidal pumping and salinity gradients ${ }^{26}$. More than half of the global coastal ocean emission is attributed to large continental shelf areas, mainly gas seeps (i.e., ebullition) and estuarine plumes (Extended Data

154 Fig.1). However, per area, methane fluxes from continental shelves are much lower compared to 155 those from other coastal ecosystems (Supplementary Table 1). We find particularly high areal 156 methane fluxes from coastal aquaculture ponds that are 7-430 times higher than from nonconverted coastal habitats (mangroves, saltmarshes, seagrasses, tidal flats) and nearly 70,000 times higher than from the open ocean ${ }^{18}$ (Supplementary Table 1).

160 Increasing aquatic methane emissions

The renewed increase in atmospheric methane has been attributed to climate-feedbacks on wetlands, increased fossil fuel use, methane production by livestock, and declining removal of methane by tropospheric $\mathrm{OH}$ (sinks) ${ }^{8,9,19}$. Our findings complement this picture by highlighting how human alterations of aquatic ecosystems increase methane emissions. The strongest growth 165 in atmospheric methane since 2007 has been reported in the tropics and subtropics $\left(30^{\circ} \mathrm{N}\right.$ to $30^{\circ} \mathrm{S}$

$16{ }^{8}$ ) with fuel burning and both agricultural and ruminant populations as the major sources ${ }^{8}$. Despite 167 the global coverage of our data, we did not detect clear latitudinal trends of methane emissions 168 from aquatic ecosystems, except for the emissions from coastal wetlands peaking at $30^{\circ} \mathrm{N}$ 169 (Extended Data Fig.2). Instead of latitudinal patterns, we found methane emissions increasing from 170 rivers to lakes and wetlands, from natural to impacted and eutrophic ecosystems (Extended Data 
171 Fig.3 and Fig.4), and from coastal marine to freshwater ecosystems (Fig.3). Particularly

172 pronounced is the difference of areal fluxes between aquaculture farms and non-converted coastal 173 and inland water ecosystems (Supplementary Table 1).

174 As a result of global warming, increased methane emissions are expected across biomes 175 and latitudes because of the higher activities of methanogenic archaea at elevated temperatures 176 relative to methanotrophic microorganisms ${ }^{27,28}$. However, not only archaea but also saprotrophic 177 fungi and cyanobacteria can produced methane under various environmental conditions ${ }^{29-31}$.

178 While the methane flux from these microorganisms is currently poorly constrained, it is intuitive 179 to assume that it increases with increasing eutrophication and temperature. This is indeed 180 supported by a general positive relationship between methane emissions and temperature across 181 biomes ${ }^{15,27}$, and the enhanced methane emissions that we found with increasing temperature in 182 coastal wetlands (Extended Data Fig.5). However, the effect of warming and wetting may have 183 synergistic effects on methane emissions from freshwater wetlands. In fact, when freshwater 184 wetlands dry, both the water table level and time of inundation drop, which may foster methane 185 oxidation and thereby reduce emissions ${ }^{32}$. Finally, global warming impacts are predicted to be 186 particularly important at high latitudes ${ }^{33}$, therefore, a better understanding of the expected changes 187 in methane emissions from the Arctic, from hydrate deposits in the shallow ocean ${ }^{34}$, permafrost 188 soils ${ }^{35}$, and melting sea ice ${ }^{36}$, for instance, would be required.

189 Human alterations (e.g. damming, rice cultivation) have increased the surface area of 190 perennial and seasonal freshwater ecosystems by $94,000 \mathrm{~km}^{2}$ and $\sim 230,000 \mathrm{~km}^{2}$, respectively, 191 between 1984 and $2014^{17}$. This areal expansion of inland waters compounds our finding of areal 192 methane fluxes from aquatic ecosystems. It also indicates that total methane fluxes from aquatic ecosystems will most likely increase due to habitat expansion and/or transformation. 

spatial and temporal variation in net emissions from production, consumption, transport pathways,

198 and due to mixing in atmosphere ${ }^{37}$. Ebullition often constitutes a significant, albeit highly variable,

199 fraction of the total aquatic methane flux. While many ecosystems have a large proportion of 200 emissions driven by ebullition (e.g. some lakes and reservoirs), other ecosystems may have negligible ebullition rates (e.g. seagrasses). Furthermore, different physical interfaces need to be considered when estimating whole-ecosystem emissions, in particular in coastal ecosystems, where methane can be released by exposed (sediment-air flux) or inundated (water-air flux) sediments following the tidal cycle ${ }^{26}$. Plant-mediated methane fluxes can be important in aquatic ecosystems dominated by plants, but the relative contribution of plant-mediated and tree fluxes to total emissions is highly uncertain at global scale ${ }^{38}$. It is also likely that there is a bias in site selection, but the direction of this bias is unknown. Very high or very low values can also be related to inadequate sampling methods, incorrect data analysis or reporting.

Another challenge lies within the statistical comparison of different upscaling methods.

210 For instance, a recent estimate of global methane emissions from freshwater wetlands was based 211 on an ensemble of 13 biogeochemical models constrained with remote sensing of surface inundation and inventory-based wetland area ${ }^{39}$. These wetland models use standardized climate,

213 atmospheric $\mathrm{CO}_{2}$, and dynamic wetland area, but to operate at global scales and across multiple 214 wetland types, the models generalize fundamental processes of methane production, oxidation, and 215 transport to the atmosphere. In contrast, here, we upscale data-driven methane fluxes from streams, 216 rivers, lakes, and reservoirs using a Monte Carlo approach, and relationships between methane 217 fluxes and either latitudinal band (streams and rivers) (Supplementary Table 3), size bin (lakes and 218 small reservoirs) or chlorophyll $a$ concentration (large reservoirs) (Supplementary Table 4). For 219 coastal ecosystems, where fewer data were available, we multiplied rates by surface area. 
221 'double counting' due to issues in clearly identifying different ecosystem types. In particular, small ponds and lakes, streams and rivers, and coastal wetlands are difficult to separate from freshwater wetlands using coarse-to-moderate spatial resolution optical and radar remote sensing. Recent wetland area mapping aims to reduce the problem of double counting by explicitly removing inland-waters from remote-sensing based surface inundation data ${ }^{40}$. However, there remains a need for finer spatial resolution approaches that would permit better mapping and counting of both small ponds and streams to partition these from vegetated wetlands.

When we combine our median bottom-up aquatic methane emissions with emissions from thermogenic, pyrogenic and other methane producing sectors ${ }^{11}$, we find a discrepancy of about 26

$230 \mathrm{Tg} \mathrm{CH}_{4} \mathrm{yr}^{-1}$ compared with bottom-up sinks ${ }^{11}$, which is similar to the difference of $+20 \mathrm{Tg} \mathrm{CH}_{4}$ $\mathrm{yr}^{-1}$ required to account for the change in atmospheric concentrations since $2007\left(7.3 \mathrm{ppb} \mathrm{yr}^{-1}\right)^{3}$ (Table 2). Our median bottom-up total source estimate exceeds the top-down sinks ${ }^{11}$ by $95 \mathrm{Tg}$ $\mathrm{CH}_{4} \mathrm{yr}^{-1}$, which is close to the source-sink imbalance of $112 \mathrm{Tg} \mathrm{CH}_{4} \mathrm{yr}^{-1}$ reported in the global methane budget ${ }^{11}$. However, our mean bottom-up global source estimate exceeds bottom-up and top-down global sinks by $188-257 \mathrm{Tg} \mathrm{CH}_{4} \mathrm{yr}^{-1}{ }^{11}$. While we are unable to explain such high sourcesink imbalances, they are consistent with the large uncertainties related to bottom-up and top-down global sinks 11,19,41. In particular, global $\mathrm{OH}$ concentrations are difficult to measure, and thus atmospheric chemistry models are used to simulate these concentrations, which vary by $10-20 \%$ 42,43. The upland soil methanotrophic sink is equally uncertain and known only via numerical modeling estimates and sparse observations made by soil chambers and flux towers ${ }^{11,44}$. Given these uncertainties, there may be room for large aquatic sources of methane to the atmosphere that we identify in our study. 
246 climate change, particularly those targeting freshwater wetlands, which account for $35-55 \%$ of

247 aquatic emissions (Table 1). Salinities of $\sim 10-15$ are an important tipping point for biogeochemical

248 processes in wetlands ${ }^{45}$, as sulfate-reducing bacteria, favored by more saline waters, can

249 outcompete methanogens. Hence, converting freshwater wetlands back to saltmarshes by restoring

250 tidal flows is a promising strategy to reduce methane emissions ${ }^{14}$, while increasing carbon sequestration. Converting aquaculture ponds and salinized rice paddies back to saltmarsh and mangrove habitats may also achieve order of magnitude reductions in methane fluxes because mangrove and saltmarshes have lower fluxes than aquaculture ponds (Supplementary Information). Reducing nutrient inputs to freshwater wetlands, lakes and reservoirs can help reduce methane emissions ${ }^{13,21}$ (Extended Data Fig.4). Reservoirs and constructed ponds can be designed to reduce methane emissions through their placement within the watershed ${ }^{46}$ and their depth ${ }^{47}$, and in the case of reservoirs, by withdrawing water from depths with lower methane concentrations ${ }^{48}$. In rivers and streams, methane emissions can be reduced if the benthic environments of the streams are restored and organic loadings are decreased ${ }^{49}$. In coastal environments, reduction of eutrophication should lead to significant decrease of methane emissions as suggested by the comparison of fluxes from impacted versus natural sites (Extended and lessen the impact on future atmospheric methane.

Because of their prominent contribution to global emissions, actions to reduce aquatic methane emissions through the management of land use, nutrient and organic inputs, and hydrological flows are a promising avenue to mitigate methane emissions. These actions will be particularly effective when targeting the ecosystems with the greatest contributions to aquatic methane emissions, primarily freshwater wetlands, lakes, reservoirs, and rice paddies. This requires an effort to integrate existing knowledge across disciplines, from the microbial processes 
that cycle methane, to the biogeochemical constraints that favor and inhibit these processes, to spatial and hydrological planning and management to create the conditions conducive to the lowest fluxes, while preserving ecosystem function and biodiversity.

\section{References (main text)}

275 1. IPCC, 2014: Climate Change 2014: Synthesis Report. Contribution of Working Groups I, II and III to the Fifth Assessment Report of the Intergovernmental Panel on Climate Change [Core Writing Team, R.K. Pachauri and L.A. Meyer (eds.)]. IPCC, Geneva, Switzerland.

2. Etminan, M., Myhre, G., Highwood, E. J. \& Shine, K. P. Radiative forcing of carbon dioxide, methane, and nitrous oxide: A significant revision of the methane radiative forcing. Geophys. Res. Lett. 43, 12,614-12,623 (2016).

3. Dlugokencky, E. J. NOAA/ESRL (www.esrl.noaa.gov/gmd/ccgg/trends_ch4/). (2019).

4. Dlugokencky, E. J. Atmospheric methane levels off: temporary pause or a new steadystate? Geophys. Res. Lett. 30, 1992 (2003).

5. Nisbet, E. G. et al. Rising atmospheric methane: 2007-2014 growth and isotopic shift. Global Biogeochem. Cycles 30, 1356-1370 (2016).

287 6. Schaefer, H. et al. A 21 st-century shift from fossil-fuel to biogenic methane emissions indicated by ${ }^{13} \mathrm{CH}_{4}$. Science 352, 80-84 (2016).

7. Rigby, M. et al. Role of atmospheric oxidation in recent methane growth. Proc. Natl. Acad. Sci. 114, 5373-5377 (2017).

291 8. Nisbet, E. G. et al. Very strong atmospheric methane growth in the 4 years 2014-2017: implications for the Paris Agreement. Global Biogeochem. Cycles 33, 318-342 (2019).

293 9. Turner, A. J., Frankenberg, C. \& Kort, E. A. Interpreting contemporary trends in atmospheric methane. Proc. Natl. Acad. Sci. 116, 2805-2813 (2019). 
10. Saunois, M. et al. The Global Methane Budget 2000-2012. Earth Syst. Sci. Data 8, 697751 (2016).

297

11. Saunois, M. et al. The Global Methane Budget 2000-2017. Earth Syst. Sci. Data 12, $1561-1623$ (2020).

12. Couto, T. B. \& Olden, J. D. Global proliferation of small hydropower plants - science and policy. Front. Ecol. Environ. 16, 91-100 (2018).

13. Beaulieu, J. J., DelSontro, T. \& Downing, J. A. Eutrophication will increase methane emissions from lakes and impoundments during the 21st century. Nat. Commun. 10, 3-7 (2019).

14. Kroeger, K. D., Crooks, S., Moseman-Valtierra, S. \& Tang, J. Restoring tides to reduce methane emissions in impounded wetlands: A new and potent Blue Carbon climate change intervention. Sci. Rep. 7, 11914 (2017).

15. Yvon-Durocher, G. et al. Methane fluxes show consistent temperature dependence across microbial to ecosystem scales. Nature 507, 488-491 (2014).

16. Harrison, J. A., Deemer, B. R., Birchfield, M. K. \& O’Malley, M. T. Reservoir water-level drawdowns accelerate and amplify methane emission. Environ. Sci. Technol. 51, 12671277 (2017).

17. Pekel, J. F., Cottam, A., Gorelick, N. \& Belward, A. S. High-resolution mapping of global surface water and its long-term changes. Nature 540, 418-422 (2016).

18. Weber, T., Wiseman, N. A. \& Kock, A. Global ocean methane emissions dominated by shallow coastal waters. Nat. Commun. 10, 1-10 (2019).

19. Hmiel, B. et al. Preindustrial ${ }^{14} \mathrm{CH}_{4}$ indicates greater anthropogenic fossil $\mathrm{CH}_{4}$ emissions. Nature 578, 409-412 (2020). methane emissions offset the continental carbon sink. Science 331, 50-50 (2011). 
21. DelSontro, T., Beaulieu, J. J. \& Downing, J. A. Greenhouse gas emissions from lakes and impoundments: Upscaling in the face of global change. Limnol. Oceanogr. Lett. 3, 64-75 (2018).

22. Deemer, B. R. et al. Greenhouse gas emissions from reservoir water surfaces: a new global synthesis. Bioscience 66, 949-964 (2016).

23. Stanley, E. H. et al. The ecology of methane in streams and rivers: patterns, controls, and global significance. Ecol. Monogr. 86, 146-171 (2016).

24. Raymond, P. A. et al. Global carbon dioxide emissions from inland waters. Nature 503, 355-359 (2013).

25. Kirschke, S. et al. Three decades of global methane sources and sinks. Nature Geoscience 6, 813-823 (2013).

26. Rosentreter, J. A., Maher, D. T., Erler, D. V, Murray, R. H. \& Eyre, B. D. Methane emissions partially offset "blue carbon" burial in mangroves. Sci. Adv. 4, eaao4985 (2018).

27. Zhu, Y. et al. Disproportionate increase in freshwater methane emissions induced by experimental warming. Nat. Clim. Chang. 10, 685-690 (2020).

28. Schulz, S., Matsuyama, H. \& Conrad, R. Temperature dependence of methane production from different precursors in a profundal sediment (Lake Constance). FEMS Microbiol. Ecol. 22, 207-213 (1997).

29. Schroll, M. et al. The stable carbon isotope signature of methane produced by saprotrophic fungi. Biogeosciences 17, 3891-3901 (2020).

30. Morana, C. et al. Methane paradox in tropical lakes? Sedimentary fluxes rather than pelagic production in oxic conditions sustain methanotrophy and emissions to the atmosphere. Biogeosciences 17, 5209-5221 (2020).

31. Bižić, M. et al. Aquatic and terrestrial cyanobacteria produce methane. Sci. Adv. 6, 
eaax5343 (2020).

32. Turetsky, M. R. et al. A synthesis of methane emissions from 71 northern, temperate, and subtropical wetlands. Glob. Chang. Biol. 20, 2183-2197 (2014).

33. Koven, C. D. et al. A simplified, data-constrained approach to estimate the permafrost carbon-climate feedback. Philos. Trans. R. Soc. A Math. Phys. Eng. Sci. 373, 20140423 (2015).

34. Zhang, M., Qiao, F. \& Song, Z. Observation of atmospheric methane in the Arctic Ocean

35. Turetsky, M. R. et al. Carbon release through abrupt permafrost thaw. Nat. Geosci. 13, 138-143 (2020).

36. He, X. et al. Sea ice in the Arctic Ocean: role of shielding and consumption of methane. Atmos. Environ. 67, 8-13 (2013).

37. Ganesan, A. L. et al. Advancing Scientific Understanding of the Global Methane Budget in Support of the Paris Agreement. Global Biogeochem. Cycles 33, 1475-1512 (2019).

38. Barba, J. et al. Methane emissions from tree stems: a new frontier in the global carbon cycle. New Phytol. 222, 18-28 (2019).

39. Poulter, B. et al. Global wetland contribution to 2000-2012 atmospheric methane growth rate dynamics. Environ. Res. Lett. 12, 094013 (2017).

40. Zhang, Z. et al. Development of a global dataset of Wetland Area and Dynamics for Methane Modeling (WAD2M). Earth Syst. Sci. Data.

41. Strode, S. A. et al. Strong sensitivity of the isotopic composition of methane to the plausible range of tropospheric chlorine. Atmos. Chem. Phys. 20, 8405-8419 (2020).

42. Zhao, Y. et al. Inter-model comparison of global hydroxyl radical $(\mathrm{OH})$ distributions and their impact on atmospheric methane over the 2000-2016 period. Atmos. Chem. Phys. 19, 13701-13723 (2019). 
43. Zhao, Y. et al. On the role of trend and variability of hydroxyl radical $(\mathrm{OH})$ in the global methane budget. Atmos. Chem. Phys. Discuss. 2011, 1-28 (2020).

44. Tian, H. et al. The terrestrial biosphere as a net source of greenhouse gases to the atmosphere. Nature 531, 225-228 (2016).

45. Wang, C., Tong, C., Chambers, L. G. \& Liu, X. Identifying the salinity thresholds that impact greenhouse gas production in subtropical tidal freshwater marsh soils. Wetlands 37, 559-571 (2017).

46. Hayes, N. M., Deemer, B. R., Corman, J. R., Razavi, N. R. \& Strock, K. E. Key differences between lakes and reservoirs modify climate signals: a case for a new conceptual model. Limnol. Oceanogr. Lett. 2, 47-62 (2017).

47. Gorsky, A. L., Racanelli, G. A., Belvin, A. C. \& Chambers, R. M. Greenhouse gas flux from stormwater ponds in southeastern Virginia (USA). Anthropocene 28, 100218 (2019).

48. Guérin, F. et al. Methane and carbon dioxide emissions from tropical reservoirs: Significance of downstream rivers. Geophys. Res. Lett. 33, 1-6 (2006).

49. Crawford, J. T. \& Stanley, E. H. Controls on methane concentrations and fluxes in streams draining human-dominated landscapes. Ecol. Appl. 26, 1581-1591 (2016).

\section{Corresponding author:}

Correspondence and requests for materials should be addressed to J.A.R.

\section{Competing financial interests:}

The authors declare no competing financial interests. 
J.A.R and B.D.E. were supported by ARC Grants DP160100248 and LP150100519. A.V.B. is a research director at the Fonds National de la Recherche Scientifique (FNRS). C.S. was supported by The Second Tibetan Plateau Scientific Expedition and Research program grant 2019QZKK0304. J.M. received funding from NASA grant NNX17AK49G. B.P. acknowledges support from the NASA Terrestrial Ecology Program and the Gordon and Betty Moore Foundation (GBMF5439). D.O. was supported by funding from the Campus Alberta Innovates Program (CAIP). Thanks to M. F. Billett, K. McKenzie, and M. Wallin for providing additional information for the streams and rivers data set. Thanks to A. Grinham, L. Gómez-Gener, T. DelSontro, K. McKenzie, and K. Delwich for providing ancillary data to the lake and reservoir data set. We thank Paul del Giorgio and Yves Prairie for providing feedback on earlier versions of this work. We thank Jian-Jhih Chen for translating several Chinese papers. Any use of trade, firm, or product names is for descriptive purposes only and does not imply endorsement by the U.S. Government.

\section{Author contributions:}

410 J.A.R. did the synthesis for mangroves, saltmarshes, seagrasses and tidal flats, and produced all

411 figures in the main manuscript; A.V.B. did the synthesis for estuaries and continental shelves;

412 A.V.B. and J.A.R. did the synthesis for aquaculture ponds; C.S. compiled the data for streams, 413 rivers, lakes, and reservoirs with help from S.L.; B.R.D. and M.A.H. updated the compiled data 414 for lakes and reservoirs and analyzed the data with input from J.M.; C.S., S.L., G.H.A. and P.A.R. 415 analyzed the data for streams and rivers; G.H.A. determined zonal estimates of river surface area 416 and stream and lake ice corrections; B.D.E. and J.A.R. conceived the project; J.A.R. drafted the 417 first manuscript and all authors reviewed and edited the manuscript and approved the final version. 418 
Figure 1. Natural log-transformed (ln) areal methane fluxes. The violin plots include boxplots showing the median and interquartile range of methane fluxes from streams and rivers, lakes, reservoirs, aquaculture (coastal and freshwater), estuaries, coastal wetlands, tidal flats and continental shelves compiled in this study. All data sets (non-log transformed) are positively skewed (skewness coefficient $>1$, range 1.1-9.8).

426

Figure 2. Global aquatic methane emissions in comparison to other methane sources and sinks. Cumulative bottom-up (BU) mean (IQR) and median ( \pm C.I.95\%) aquatic methane emissions estimated in this study compared to other BU methane sources versus BU and top-down

430 (TD) methane sinks from Saunois et al. ${ }^{11}$ (Table 2). The coastal and open ocean estimate includes emissions from estuaries, saltmarshes, mangroves, seagrasses, tidal flats, coastal aquaculture ponds, continental shelves, slope and the open ocean ${ }^{18}$. Error estimates for freshwater wetland and rice emissions are based on inventory and biogeochemical modelling efforts, therefore show comparably low variability and uncertainty. 
443 Annual methane emissions from aquatic ecosystems. We present median, first (Q1) and third 444 (Q3) quartile, mean and 95\% confidence intervals of bottom-up global methane emissions. 445 Although two decimal places imply more accuracy than the methods provide, this was done to 446 avoid losing the emission estimates from ecosystems with $<1 \mathrm{Tg} \mathrm{CH}_{4} \mathrm{yr}^{-1}$.

\begin{tabular}{|c|c|c|c|}
\hline \multirow[t]{2}{*}{ Aquatic ecosystem } & \multicolumn{2}{|c|}{$\begin{array}{l}\text { Bottom-up global methane emission } \\
\qquad\left(\mathrm{Tg} \mathrm{CH}_{4} \mathrm{yr}^{-1}\right)\end{array}$} & \multirow[t]{2}{*}{ Reference } \\
\hline & Median (Q1-Q3) & Mean $( \pm$ C.I. $95 \%)$ & \\
\hline Rivers (ice-corrected) & $5.8(1.8-21.0)$ & $30.5 \pm 17.1$ & This study \\
\hline \multicolumn{4}{|l|}{ Lakes (ice-cover, ice-melt corrected) } \\
\hline$<0.001 \mathrm{~km}^{2}$ & $21.2(9.1-53.5)$ & $54.5 \pm 48.5$ & This study \\
\hline $0.001-0.01 \mathrm{~km}^{2}$ & $13.2(5.6-33.1)$ & $31.1 \pm 23.7$ & This study \\
\hline $0.01-0.1 \mathrm{~km}^{2}$ & $4.4(1.4-16.7)$ & $22.4 \pm 18.4$ & This study \\
\hline $0.1-1 \mathrm{~km}^{2}$ & $3.0(1.1-8.0)$ & $9.9 \pm 7.0$ & This study \\
\hline$>1 \mathrm{~km}^{2}$ & $14.0(6.0-31.0)$ & $33.0 \pm 45.0$ & This study \\
\hline All lakes & $55.8(23.3-142.3)$ & $150.9 \pm 73.0$ & This study \\
\hline \multicolumn{4}{|l|}{ Reservoirs (ice-cover, ice-melt corrected) } \\
\hline$<1 \mathrm{~km}^{2}$ & $0.4(0.1-1.3)$ & $2.4 \pm 4.7$ & This study \\
\hline$>1 \mathrm{~km}^{2}$ & $14.7(8.7-27.1)$ & $22.0 \pm 6.4$ & This study \\
\hline All reservoirs & $15.1(8.8-28.4)$ & $24.3 \pm 8.0$ & This study \\
\hline Freshwater wetlands & $150.1(138.3-164.6)$ & $148.6 \pm 15.2$ & Saunois et al. ${ }^{11}$ (A) \\
\hline Freshwater aquaculture ponds & $4.4(0.4-7.9)$ & $14.0 \pm 18.8$ & This study \\
\hline Rice cultivation & $29.9(24.9-32.1)$ & $29.8 \pm 6.7$ & Saunois et al. ${ }^{11}$ (B) \\
\hline Total inland waters & $261.0(197.5-396.2)$ & $398.1 \pm 79.4$ & This study \\
\hline Estuaries & $0.23(0.02-0.91)$ & $0.90 \pm 0.29$ & This study \\
\hline \multicolumn{4}{|l|}{ Coastal wetlands } \\
\hline Saltmarshes & $0.18(0.02-0.89)$ & $2.00 \pm 1.51$ & This study \\
\hline Mangroves & $0.21(0.06-0.77)$ & $1.46 \pm 0.91$ & This study \\
\hline Seagrasses & $0.13(0.07-0.21)$ & $0.18 \pm 0.19$ & This study \\
\hline Tidal flats & $0.17(0.04-2.7)$ & $4.2 \pm 4.9$ & This study \\
\hline Coastal aquaculture ponds & $0.62(0.01-1.0)$ & $5.9 \pm 15.1$ & This study \\
\hline Continental shelves & $5.7(3.6-20.4)$ & $17.2 \pm 34.0$ & This study \\
\hline Slope (200-2000m) & $0.30(0.23-0.40)$ & $0.36 \pm 0.93$ & Weber et al. ${ }^{18}(\mathrm{C})$ \\
\hline Open ocean (> 2000 m) & $0.91(0.75-1.1)$ & $1.0 \pm 1.7$ & Weber et al. ${ }^{18}(\mathrm{C})$ \\
\hline Total coastal and open ocean & $8.4(4.8-28.4)$ & $33.2 \pm 37.6$ & This study \\
\hline Total aquatic & $269.4(202.3-424.6)$ & $431.3 \pm 87.9$ & This study \\
\hline
\end{tabular}

448 (A) Based on 13 biogeochemical models for wetland emissions, bottom-up estimate year 2008-2017

(B) Based on 5 inventory models for rice cultivation, bottom-up estimate year 2008-2017

(C) Based on 2 machine-learning methods; confidence interval is mean of the lower and upper bound of the $95 \%$ level 
Bottom-up (BU) global aquatic methane sources compared to other BU natural and anthropogenic methane sources and BU and top-down (TD) methane sinks.

\begin{tabular}{|c|c|c|c|c|}
\hline & $\begin{array}{l}\text { Average methane } \\
\text { emissions } \\
\left(\mathrm{Tg} \mathrm{CH}_{4} \mathrm{yr}^{-1}\right)\end{array}$ & $\begin{array}{l}\text { Range of methane } \\
\text { emissions } \\
\left(\mathrm{Tg} \mathrm{CH}_{4} \mathrm{yr}^{-1}\right)\end{array}$ & Period of time & Reference \\
\hline \multicolumn{5}{|l|}{ Aquatic sources } \\
\hline $\mathrm{BU}(\mathrm{A})$ & 352 & $253-455$ & $(2008-2017)$ & Saunois et al. ${ }^{11}$ \\
\hline BU (median, Q1-Q3) & 269 & $202-424$ & $(1978-2019)$ & This study \\
\hline BU (mean, lower- upper C.I.95\%) & 431 & $343-519$ & $(1978-2019)$ & This study \\
\hline \multicolumn{5}{|l|}{ Non-aquatic sources } \\
\hline \multicolumn{5}{|l|}{ Natural sources (BU) } \\
\hline Geological (onshore) & 38 & $13-53$ & $(2008-2017)$ & Saunois et al. ${ }^{11}$ \\
\hline Wild animals & 2 & $1-3$ & $(2008-2017)$ & Saunois et al. ${ }^{11}$ \\
\hline Termites & 9 & $3-15$ & $(2008-2017)$ & Saunois et al. ${ }^{11}$ \\
\hline \multicolumn{5}{|l|}{ Anthropogenic sources (BU) } \\
\hline \multicolumn{5}{|l|}{ Agriculture and waste } \\
\hline Enteric fermentation \& manure & 111 & $106-116$ & $(2008-2017)$ & Saunois et al. ${ }^{11}$ \\
\hline Landfills \& waste & 65 & $60-69$ & $(2008-2017)$ & Saunois et al. ${ }^{11}$ \\
\hline \multicolumn{5}{|l|}{ Fossil fuels } \\
\hline Coal mining & 42 & $29-60$ & $(2008-2017)$ & Saunois et al. ${ }^{11}$ \\
\hline Oil \& Gas & 79 & $66-92$ & $(2008-2017)$ & Saunois et al. ${ }^{11}$ \\
\hline Industry & 3 & $0-7$ & $(2008-2017)$ & Saunois et al. ${ }^{11}$ \\
\hline Transport & 4 & $1-12$ & $(2008-2017)$ & Saunois et al. ${ }^{11}$ \\
\hline \multicolumn{5}{|l|}{ Biomass \& biofuel burning } \\
\hline Biomass burning & 17 & $14-26$ & $(2008-2017)$ & Saunois et al. ${ }^{11}$ \\
\hline Biofuel burning & 12 & $10-14$ & $(2008-2017)$ & Saunois et al. ${ }^{11}$ \\
\hline \multicolumn{5}{|l|}{ Total methane sources } \\
\hline $\mathrm{BU}(\mathrm{B})$ & 737 & $594-881$ & $(2008-2017)$ & Saunois et al. ${ }^{11}$ \\
\hline BU (median, Q1-Q3) & 651 & $505-892$ & $(1978-2019)$ & This study \\
\hline BU (mean, lower- upper C.I.95\%) & 813 & $646-986$ & $(1978-2019)$ & This study \\
\hline \multicolumn{5}{|l|}{ Total methane sinks } \\
\hline $\mathrm{BU}$ & 625 & $500-798$ & $(2008-2017)$ & Saunois et al. ${ }^{11}$ \\
\hline $\mathrm{TD}$ & 556 & $501-574$ & $(2008-2017)$ & Saunois et al. ${ }^{11}$ \\
\hline
\end{tabular}

(A) Includes estimates for wetlands, freshwater, oceanic sources, permafrost and rice cultivation

Saunois et al. ${ }^{11}$

459 (B) Differences of $3 \mathrm{Tg} \mathrm{CH}_{4} \mathrm{yr}^{-1}$ compared to the sum of aquatic and non-aquatic sources (BU) (2008-2017) of 734 
Methods:

We use the term 'natural' to describe less impacted and less disturbed study sites or ecosystems, whereas 'impacted' refers to highly impacted, modified, polluted or eutrophied study sites or ecosystems.

Our datasets were compiled from peer-reviewed publications. Temporal (annual, seasonal, diel) or spatial data were averaged to a single flux per study site. If 'site' was not obvious, we set a criterion of $10 \mathrm{~km}$ distance to distinguish between sites. An exception was the river and stream data set, where measurements with the exact same coordinates were treated as one site, and fluxes with different coordinates were treated as many sites to account for variable fluxes of low and high stream orders. Values under detection limit were set to " 0 " and included in the statistical analysis. Sites were classified as 'natural' or 'impacted' if clearly identified in the literature, or based on the authors' knowledge.

\section{Rivers and streams}

We compiled peer reviewed studies until March 2019 using the Boolean search string "( $\mathrm{CH}_{4}$ OR methane) AND (concentration OR flux OR emission) AND (river OR stream)" in the Web of Science Core Collection (http://isiknowledge.com) and China Knowledge Resource Integrated database (https://www.cnki.net/). In our river and stream database, we only included georeferenced methane concentrations or fluxes. If exact coordinates were not provided but site description was sufficient, we obtained approximate coordinates from Google Maps. We excluded non-river data by either referring to the original site descriptions or by overlying the measurement locations with a map of global open inland waters ${ }^{50}$.

Our efforts identified a total of 2,601 records with either a methane concentration or a flux measurement. Our primary analysis showed that methane fluxes calculated from concentration versus gas transfer velocity $(k)$ poorly predicted the literature reported fluxes. Therefore, we only 
included reported methane fluxes from publications. This resulted in a collection of 652 methane

489 fluxes from 74 publications including one unpublished data set (provided by T.I.B). The total

490 number of records included 187 total fluxes, 590 diffusive fluxes and 126 ebullitive methane

491 fluxes. We refer to the total methane flux as either the sum of diffusive and ebullitive fluxes or the

492 total flux without differentiation between diffusion and ebullition. For example, a properly

493 designed chamber can catch both diffusive and ebullitive methane fluxes ${ }^{51,52}$. If the original

494 studies clearly identify chamber fluxes as diffusive + ebullitive fluxes, we included these as total

495 fluxes. If the original studies identified chamber fluxes as diffusive (e.g., because of low observed

496 ebullition) or reported calculated fluxes from concentration and $k$, we included these as diffusive

497 fluxes. If the original studies measured methane fluxes with bubble traps or invert funnels, we

498 included these as ebullitive fluxes.

499 We used a Monte Carlo approach to upscale river methane fluxes at the global scale and to

500 estimate uncertainties. We performed simulations for five latitudinal bands $\left(0-10^{\circ}, 10-25^{\circ}, 25-40^{\circ}\right.$,

$50140-60^{\circ}, 60-90^{\circ}$ ) and at the global scale for diffusive, ebullitive and total fluxes. Because the data

502 were skewed, we natural-log $(\ln )$ transformed all fluxes prior to simulations. For each simulation,

503 we generated a total of 1,000 random values from a normal distribution centered around means of

504 the $\ln$ methane fluxes and with deviations confined by those of the $\ln$ methane fluxes (R package

$505 \mathrm{mc} 2 \mathrm{~d})$. Values generated from the simulations were then back-transformed to raw fluxes before

506 calculation of any statistics. Global methane emissions were calculated as the products of the

507 recently-developed Global River Widths from Landsat (GRWL) surface area ${ }^{53}$ and the post-

508 simulation methane fluxes for each latitudinal band (Supplementary Table 4). Finally, we

509 corrected our latitudinal methane emissions for ice coverage periods by excluding GRWL surface

510 areas ${ }^{53}$ with an atmospheric temperature below $-4{ }^{\circ} \mathrm{C}$ for each month in each latitudinal band and

511 at the global scale ${ }^{54}$. 


\section{Lakes and reservoirs}

514 We conducted a literature search until May 2019 using "( $\mathrm{CH}_{4}$ OR methane) AND

515 (concentration OR flux OR emission) AND (lake OR pond OR reservoir)" in the same search

516 engines used for rivers and streams. Overall, the 84 publications provided 243 and 116 total

517 methane fluxes for 227 lakes and 86 reservoirs, respectively. In our freshwater lakes, ponds and

518 reservoir database, we included studies that provided both diffusive and ebullitive fluxes from the

519 open water surface either separately (e.g. via bubble traps or acoustic surveys for ebullition and

520 via thin boundary layer modelling or floating chambers for diffusion) or together (e.g. via floating

521 chamber or eddy covariance methods). We categorized 'site' as either a lake or a reservoir, wherein

522 a reservoir was defined as a system whose primary outflow was dammed. The lake category was

523 largely comprised of natural lakes, and a small subset $(\mathrm{n}=23)$ of artificial lakes ${ }^{55,56}$. The total

524 methane flux refers either to the total emission estimate (diffusive + ebullitive) of the whole water

525 body reported by the authors; or was estimated by us using the mean of all reported areal fluxes

526 (diffusive and ebullitive) or the mean of the range of reported fluxes (diffusive and ebullitive). We

527 excluded studies that estimated only diffusive or ebullitive methane fluxes, but not both. We only

528 include studies where both diffusive and ebullitive fluxes were estimated because the extent to

529 which each contributes to total emissions is variable (ranging from negligible to most the flux) ${ }^{57}$.

530 We further excluded methane fluxes that were made solely during mixing events, and fluxes from

531 adjacent marsh and drawdown zones of reservoirs because they should be accounted for in

532 freshwater wetland emissions. Finally, we also excluded methane fluxes from beaver ponds and

533 river reaches upstream of weirs to avoid potential overlap with river and stream emissions. If

534 original studies used an $r^{2}>0.85$ as a cut-off for linear gas accumulation in floating chambers,

535 these fluxes were considered diffusive only and excluded from the dataset (unless accompanied

536 by an independent estimate of ebullition). 
538 total lentic methane emissions ${ }^{21,22}$, we used total phosphorus (TP) to model missing chlorophyll $539 a$ data and assigned trophic statuses ${ }^{22}$. If no estimates of chlorophyll $a$ or TP were reported by the 540 primary study, we mined the literature for other studies of the same site that reported TP and/or 541 chlorophyll $a$ within a +/- five-year time period of the primary study.

542 We upscaled lake and reservoir methane fluxes separately to a global scale. For each water 543 body type, we used a Monte Carlo analysis ( $\mathrm{R}$ package $\mathrm{mc} 2 \mathrm{~d}$ ) that allowed for uncertainty in both 544 surface area and areal methane fluxes. Only sites with surface area information were included in 545 the Monte Carlo analysis ( $\mathrm{n}=198$ lakes, $\mathrm{n}=78$ reservoirs). Because the data were skewed, we $\ln$ 546 transformed all total fluxes prior to Monte Carlo analysis. Our approach for binning Monte Carlo 547 analyses differed for lakes versus reservoirs due to different correlates with methane emissions ${ }^{57}$. 548 In a parallel study, we show that morphometric features better predicted methane emission in lakes, 549 whereas chlorophyll $a$ was a better predictor in reservoirs ${ }^{57}$.

$550 \quad$ For small lakes $<1 \mathrm{~km}^{2}$, we upscaled methane fluxes based on logarithmic size classes. 551 However, for lakes $>1 \mathrm{~km}^{2}$, our low sample size $(\mathrm{n}=20)$ precluded this approach, and we lumped 552 together all lakes $>1 \mathrm{~km}^{2}$. We ran a Monte Carlo analysis with 1,000 iterations for each size553 classes of small lakes and for large lakes as one category. Each iteration randomly selected a methane flux from a normal distribution surrounding the mean and standard deviation for that size class. Simulations also selected for a surface area estimate of lakes in each size class using a 556 uniform distribution based on estimates from ${ }^{58-60}$. Because Verpoorter et al. ${ }^{60}$ report combined 557 lake and reservoir surface area, we subtracted reservoir areas using estimates of reservoir surface 558 area for each size class from Lehner et al. ${ }^{61}$. Because surface area estimates for lakes $<0.01 \mathrm{~km}^{2}$ 559 are highly uncertain, we extrapolated the data from Verpoorter et al. ${ }^{60}$ to estimate the lower bound 560 62. 

reservoirs. For small reservoirs, where sample size was low $(n=16)$, we used the same scaling approach as with large lakes. For large reservoirs, where estimates of the global distribution of

564 lake and reservoir chlorophyll $a$ were available ${ }^{63}$, we upscaled methane fluxes based on the 565 positive log-linear relationship between chlorophyll $a$ and areal methane fluxes ${ }^{57}$ and reservoir 566 surface area estimates ${ }^{58,61}$. We generated 1,000 Monte Carlo simulations of reservoir surface area based on a uniform distribution ranging between the surface area estimates by Downing et al. ${ }^{58}$ and Lehner et al. ${ }^{61}$. We also allowed for uncertainty in the relationship between chlorophyll $a$ and methane flux by generating 1,000 Monte Carlo simulations of slope and intercept terms based on a normal distribution around the standard error of these terms. We then estimated areal methane fluxes by applying reservoir surface areas across 20 chlorophyll $a$ bins (with each bin spanning 5 $\mu \mathrm{g} \mathrm{L}^{-1}$ from 0-100 $\mu \mathrm{g} \mathrm{L}^{-1}$ ), then calculating total methane emissions from each bin, and finally summing across the 20 bins. The global distributions of chlorophyll $a$ concentrations were generated using MERIS OC4 satellite imagery via the MTRI method which is based on $300 \mathrm{~m}$ resolution inputs ${ }^{63}$.

To account for the impact of ice on lake and reservoir emissions, we excluded surface areas

$577{ }^{61}$ with an average atmospheric temperature of $0{ }^{\circ} \mathrm{C}$ or less for each month ${ }^{54}$. For lakes and 578 reservoirs that freeze, we scaled upwards the ice-corrected emissions by $127 \%{ }^{64}$ to account for an 579 ice-melt pulse in emissions. Both the ice cover and ice melt corrections were applied after the 580 Monte Carlo upscaling by adjusting the estimated annual flux by the size class specific fraction of 581 emission expected based on both ice cover and ice melt (fractions ranged from 0.60 to 0.98 , 582 Supplementary Table 4). Combined corrections for both ice cover and ice melt reduced overall annual methane emissions to $66 \%$ of their uncorrected values. We do not account for potential diel effects on lentic methane emissions. A further uncertainty is our small sample size for large lakes 
$585\left(>1 \mathrm{~km}^{2}\right)$, and that half of the large lakes were shallow ( $\leq 3 \mathrm{~m}$ mean depth), and only 3 were $>100$

$586 \mathrm{~km}^{2}$ suggesting emissions may be overestimated from this size class.

587

\section{Freshwater aquaculture ponds}

We conducted a literature search using " $\left(\mathrm{CH}_{4} \mathrm{OR}\right.$ methane) AND (aquaculture pond OR aquaculture farm) AND (shrimp OR fish)". For freshwater aquaculture ponds, we built on the database from Yuan et al. ${ }^{65}$ and added three new studies of diffusive and ebullitive methane fluxes since 2018. Total freshwater aquaculture pond fluxes in the database were derived mainly from carp and mixed shrimp-fish ponds. We scaled areal freshwater aquaculture methane fluxes to global emissions using to the surface area estimated by Verdegem and Bosma ${ }^{66}$ (Supplementary Table 5), which is likely an underestimate assuming an increase of freshwater aquaculture farms since 2009.

\section{Coastal ocean}

For each coastal ocean ecosystem, we performed a literature review until December 2019

600 using 'Scopus' by Elsevier (https://www.scopus.com/) and 'Google Scholar' 601 (https://scholar.google.com/) databases. Additionally, we scanned the reference lists of 602 publications. When methane fluxes were only presented in figures, we used a manual data 603 extraction tool (WebPlotDigitizer) to estimate the values. We included methane fluxes with 604 identifiable coordinates (latitude/longitude) derived from the original studies or from Google Earth 605 based on site description. Coastal wetlands were distinguished from inner estuaries by accounting 606 for methane fluxes solely from studies that were conducted in clearly vegetation-dominated marsh, 607 seagrass or mangrove sites in opposition to spatial surveys over salinity gradients in estuarine open 608 waters. For each coastal ocean ecosystem, we upscaled combined spatial and temporal methane 609 fluxes to a global scale using recent surface area estimates (Supplementary Table 5). 
613 in 53 publications containing 137 averaged water-air methane fluxes for 124 sites. In our estuary

614 database, we included methane fluxes over full salinity gradients (freshwater to seawater). We

615 excluded methane fluxes from coastal wetlands and from incomplete coverage of salinity 616 gradients. Most studies reported diffusive methane fluxes computed from concentration gradients

617 and $k$ parameterizations. A minority $(\mathrm{n}=3)$ of the studies measured diffusive fluxes with floating 618 chambers, and only one study reports measurements with eddy-covariance. If the original studies 619 estimated fluxes using several $k$ parameterizations, we chose the value corresponding to the 620 parameterization most accepted (e.g., we chose the Wanninkhof ${ }^{67}$ over the Liss and Merlivat ${ }^{68}$ 621 model).

\section{Saltmarshes}

We conducted a literature search using “ $\left(\mathrm{CH}_{4} \mathrm{OR}\right.$ methane) AND (saltmarsh OR saltmarsh OR tidal marsh)", which resulted in 75 publications containing 89 averaged methane fluxes for 60 sites. In our saltmarsh database, we included methane flux estimates and measurements for saltmarsh and tidal marsh. We excluded methane fluxes from freshwater marsh (salinity $<0.5)$ that should be accounted for in freshwater wetland emissions. Saltmarsh methane fluxes were grouped into three salinity classes: oligohaline (0.5-5), mesohaline (5-18), and polyhaline (>18) ${ }^{69}$. Most

630 studies $(n=49)$ reported diffusive methane fluxes from the sediment-air interface during low tide using static chambers. Several other studies $(n=33)$ determined sediment-water-air fluxes during exposed and inundated periods using either static dynamic chambers or eddy covariance. Few

633 studies $(n=7)$ were available that determined the water-air methane flux, either computed based on $634 k$ parameterization or using the floating chamber approach. 
We conducted a literature search using " $\left(\mathrm{CH}_{4} \mathrm{OR}\right.$ methane) AND (mangroves $\mathrm{OR}$ mangrove forest)", which resulted in 56 publications containing 79 averaged methane fluxes for 59 sites. Our global mangrove methane emission estimate is an update of the review by Rosentreter et al. ${ }^{26}$. In our mangrove database, we included sediment-water fluxes from core incubations $(\mathrm{n}=$ 2), sediment-air $(n=45)$ and sediment-water-air fluxes $(n=8)$ using static chambers, and water-air fluxes $(n=22)$ using floating chambers or based on $k$ parameterizations. Our revised global estimate includes mainly diffusive sediment-air and water-air fluxes, but also plant-mediated fluxes

644 (through pneumatophores, roots, stems, leaves), and fluxes over sediments with crab burrows. No estimates of ebullitive fluxes from mangroves were available. We excluded fluxes estimated from methane concentrations in gas bubbles that were actively stirred up from mangrove sediments, as they cannot be accounted for in situ ebullition.

\section{Seagrasses}

We conducted a literature search using "( $\mathrm{CH}_{4}$ OR methane) AND (seagrasses OR seagrass beds OR seagrass meadows)", which resulted in 11 publications containing 18 averaged methane fluxes for 18 sites. In our seagrass database, we included plant-mediated and diffusive sedimentwater fluxes $(n=14)$ from submerged seagrass meadows and few available water-air methane

654 fluxes $(n=4)$ over seagrass meadows. The majority of studies reported sediment-water fluxes from core incubation and benthic chambers. One study used a dynamic flux chamber, which allowed flux measurements during exposed and submersed conditions, hence includes sediment-air fluxes 
661 OR sand flat)", which resulted in 23 publications containing 25 averaged methane fluxes for 16 662 sites. Tidal flat ecosystems were classified as tidal mudflats (unconsolidated fine-grain sediments), 663 tidal sand flats (unconsolidated coarse-grain sediments), and wide tidal rock-platforms 664 (consolidated sediments, organic material or rocks) ${ }^{71}$ and distinguished from coastal wetlands 665 through the absence of vegetation. Because tidal flats comprise at least a global distribution of $666127,921 \mathrm{~km}^{2} 71$, which is similar to that of mangrove forests, and are characterized by frequent 667 tidal inundation, we included tidal flats in our coastal ocean emission estimates. Our tidal flat data 668 set is biased towards tidal mudflats in China, with a few data from North America and Europe. We 669 included diffusive and ebullitive fluxes from coastal bare sediments of the inter-tidal zone (salinity $670>0.5)$ measured with static chambers or core incubations, which resulted in 16 sediment-air fluxes, 6718 sediment-water-air fluxes and one water-air flux. We excluded freshwater bare sediments and 672 sites where the salinity region was unclear.

673

674

676

677

678

680 681 682 683

\section{Coastal aquaculture ponds}

We conducted a literature search using " $\left(\mathrm{CH}_{4} \mathrm{OR}\right.$ methane) $\mathrm{AND}$ (aquaculture pond OR aquaculture farm) AND (shrimp OR fish)", which resulted in 10 publications containing 18 methane fluxes for 5 sites. Most methane fluxes $(n=10)$ were from studies conducted in coastal aquaculture ponds near the Min River estuary in China. In our coastal aquaculture database, we included diffusive and ebullitive fluxes mainly from shrimp ponds, with the residual measurements from mixed fish-shrimp, mixed shrimp-sea cucumber, drained and undrained coastal aquaculture farms. 

areas', if identified as such in the literature, or based on the authors' knowledge. We conducted a literature search using “ $\left(\mathrm{CH}_{4} \mathrm{OR}\right.$ methane) AND (shelf OR coastal) AND (Arctic ocean OR upwelling OR river plume)", which resulted in 77 publications providing 9 methane fluxes for estuarine plumes, 19 for seep areas (diffusion), 3 for seep areas (ebullition), 12 for upwelling areas, and 57 for other continental shelf areas. In our continental shelf database, we included methane water-air flux estimates or measurements for continental shelf environments. We excluded studies that reported only the dissolved methane concentrations without computing fluxes. We summed our upscaled emissions from estuarine plumes, seep areas (diffusion + ebullition), upwelling areas, the East Siberian Arctic Shelf, and other continental shelves to total global continental shelf methane emissions.

695

696

\section{Statistical analysis}

697 We use the interquartile range (IQR) to describe methane flux variability, and the $95 \%$ confidence intervals (C.I.95\%) (using the population standard deviation $(\sigma)$ and sample size (n) assuming Student-T distribution and a confidence level of $\alpha=1-0.95=0.05)$ to estimate uncertainties of mean methane fluxes. For global estimates, we combined the confidence intervals by taking the square root of the sum of the variances. We applied the function 'skewness' from the R package e1071 (R Core Team, RStudio, version 1.2.5019) to compute the skewness coefficient of each data set. We did not conduct an assessment for publication bias.

\section{Data availability:}

706 The datasets that support the findings of this study are available in the "figshare" repository, 10.6084/m9.figshare.13611296. 
710

711

712

713

714

715

716

717

718

719

720

721

722

723

724

725

726

727

728

729

730

731

732

733

50. Lehner, B. \& Döll, P. Development and validation of a global database of lakes, reservoirs and wetlands. J. Hydrol. 296, 1-22 (2004).

51. Cole, J. J., Bade, D. L., Bastviken, D., Pace, M. L. \& Van de Bogert, M. Multiple approaches to estimating air-water gas exchange in small lakes. Limnol. Oceanogr. Methods 8, 285-293 (2010).

52. Gålfalk, M., Bastviken, D., Fredriksson, S. \& Arneborg, L. Determination of the piston velocity for water-air interfaces using flux chambers, acoustic Doppler velocimetry, and IR imaging of the water surface. J. Geophys. Res. Biogeosciences 118, 770-782 (2013).

53. Allen, G. H. \& Pavelsky, T. Global extent of rivers and streams. Science 361, 585-588 (2018).

54. Fick, S. E. \& Hijmans, R. J. WorldClim 2: new 1-km spatial resolution climate surfaces for global land areas. Int. J. Climatol. 37, 4302-4315 (2017).

55. Grinham, A. et al. The importance of small artificial water bodies as sources of methane emissions in Queensland, Australia. Hydrol. Earth Syst. Sci. 22, 5281-5298 (2018).

56. van Bergen, T. J. H. M. et al. Seasonal and diel variation in greenhouse gas emissions from an urban pond and its major drivers. Limnol. Oceanogr. 64, 2129-2139 (2019).

57. Deemer, B. R. \& Holgerson, M. A. Drivers of methane flux differ between lakes and reservoirs, complicating global upscaling efforts. J. Geophys. Res. Biogeosciences (accepted).

58. Downing, J. A. et al. The global abundance and size distribution of lakes, ponds, and impoundments. Limnol. Oceanogr. 51, 2388-2397 (2006).

59. Downing, J. A. Emerging global role of small lakes and ponds: Little things mean a lot. Limnetica 29, 9-24 (2010).

60. Verpoorter, C., Kutser, T., Seekell, D. A. \& Tranvik, L. J. A global inventory of lakes 
based on high-resolution satellite imagery. Geophys. Res. Lett. 41, 6396-6402 (2014).

735

736

737

738

739

740

741

742

743

744

745

746

747

748

749

750

751

752

753

754

755

756

757

758

61. Lehner, B. et al. High-resolution mapping of the world's reservoirs and dams for sustainable river-flow management. Front. Ecol. Environ. 9, 494-502 (2011).

62. Holgerson, M. A. \& Raymond, P. A. Large contribution to inland water $\mathrm{CO}_{2}$ and $\mathrm{CH}_{4}$ emissions from very small ponds. Nat. Geosci. 9, 222-226 (2016).

63. Sayers, M. J. et al. A new method to generate a high-resolution global distribution map of lake chlorophyll. Int. J. Remote Sens. 36, 1942-1964 (2015).

64. Denfeld, B. A., Baulch, H. M., del Giorgio, P. A., Hampton, S. E. \& Karlsson, J. A synthesis of carbon dioxide and methane dynamics during the ice-covered period of northern lakes. Limnol. Oceanogr. Lett. 3, 117-131 (2018).

65. Yuan, J. et al. Rapid growth in greenhouse gas emissions from the adoption of industrialscale aquaculture. Nat. Clim. Chang. 9, 318-322 (2019).

66. Verdegem, M. C. J. \& Bosma, R. H. Water withdrawal for brackish and inland aquaculture, and options to produce more fish in ponds with present water use. Water Policy 11, 52-68 (2009).

67. Wanninkhof, R. Relationship between wind speed and gas exchange over the ocean. $J$. Geophys. Res. 97, 7373-7382 (1992).

68. Liss, P. S. \& Merlivat, L. Air-sea gas exchange rates: introduction and synthesis. in The Role of Air-Sea Exchange in Geochemical Cycling 113-127 (Springer Netherlands, 1986).

69. Poffenbarger, H. J., Needelman, B. A. \& Megonigal, J. P. Salinity influence on methane emissions from tidal marshes. Wetlands 31, 831-842 (2011).

70. Bahlmann, E. et al. Tidal controls on trace gas dynamics in a seagrass meadow of the Ria Formosa lagoon (southern Portugal). Biogeosciences 12, 1683-1696 (2015).

71. Murray, N. J. et al. The global distribution and trajectory of tidal flats. Nature 565, 222225 (2018). 